\title{
Outbreak of measles in an unvaccinated population, British Columbia, 2014
}

\author{
Naus $M^{1,2 *}$, Puddicombe $D^{1}$, Murti $M^{3}$, Fung $C^{3}$, Stam $R^{3}$, Loadman $S^{3}$, Krajden $M^{1,2}$, Tang $P^{1,2}$, Lem $M^{2,3}$ \\ ${ }^{1}$ British Columbia Centre for Disease Control, Vancouver, BC \\ ${ }^{2}$ Faculty of Medicine, University of British Columbia, Vancouver, BC \\ ${ }^{3}$ Fraser Health Authority, Surrey, BC
}

*Correspondence: monika.naus@bccdc.ca

\section{Abstract}

Background: Although Canada eliminated endemic measles in 1998, outbreaks are expected to occur periodically through import-related transmission in geographically clustered unvaccinated communities. In the spring of 2014, in association with an outbreak in the Netherlands, a large measles outbreak occurred in British Columbia in a community unvaccinated for religious reasons.

Methods: Case finding with assistance of the local community, its school and religious leaders and local health care providers was conducted to identify confirmed, probable and suspect cases. Measles control guidelines were implemented with limited uptake of measles-containing vaccine (MCV) but higher adherence with infection control measures and travel restrictions.

Results: A total of 433 cases ( 325 confirmed and 108 probable) were identified. Rash onset ranged from February 22 to June 9, with $98 \%$ during March and April. Fifty-seven percent of cases were students of one school. The median age of cases was 11 years and $68 \%$ of cases were aged five to 19 years. Ninety-nine percent of cases were unvaccinated. One case had encephalitis and recovered. Only five cases occurred outside of the affected community. Genotyping results were consistent with importation from the Netherlands outbreak.

Conclusion: This outbreak in a community with low-vaccination rates affected largely the pediatric-age population, compatible with acquisition of measles immunity by adult members due to prior wild-type measles infection. Although vaccine hesitancy persisted in this population, containment of the outbreak was facilitated by a high degree of community cooperation with infection control measures and restriction of movement.

\section{Introduction}

Measles is a highly contagious, acute viral illness preventable by measles vaccine. To achieve the Pan American Health Organization (PAHO) goal of measles elimination, British Columbia (BC) introduced a two-dose measles vaccination program for children in $1996(1,2)$. Canada has been free of endemic measles (defined as an identifiable chain of transmission lasting over 12 months) since 1998 and measles was declared eliminated in the Americas in 2002. The status of measles elimination has been recently reviewed by the International Expert Committee (3).

Measles cases and outbreaks continue to occur in Canada due to periodic importation. Since Canada has been free of endemic measles, BC has experienced two substantial outbreaks. The first outbreak in 2010 resulted in 82 confirmed and clinical (also referred to as 'probable') cases with province-wide transmission and was associated with two separate importations during the Winter Olympic Games held in Vancouver $(4,5)$. The second and substantially larger outbreak occurred in 2014 and is described in this report.

The 2014 outbreak occurred in the eastern part of the Fraser Valley health region in a Netherlands Reformed Orthodox Protestant community with a population estimated at 1,200 individuals. This community is known to object to vaccination. This population is not socially or geographically isolated, resides in a semi-rural agricultural part of the region and has strong ties to the Netherlands. The outbreak occurred at the tail end of a measles outbreak in the Netherlands which had begun in May 2013 and ended in March 2014. The Netherlands outbreak resulted in approximately 2,600 reported cases of measles, 182 hospitalizations among children and the death of 
one child from complications of measles $(6,7)$. The same Netherlands outbreak had resulted in two earlier importations into the Fraser Health Authority region in August and November 2013, neither of which resulted in widespread transmission and an importation of measles into Southern Alberta resulting in 42 confirmed cases from October 2013 through January 2014 (8).

\section{Outbreak investigation}

On March 6, 2014, Fraser Health Authority was notified by the principal of a school in the eastern part of the region that about one-third of a grade three class and about $10 \%$ of the remaining students were absent from school due to a rash illness. Almost all students at the school were not vaccinated against measles due to religious belief.

The health unit initiated case confirmation and case finding by calling families of school children to identify earlier and current cases. The school families characteristically had a large number of children per family and a high degree of interconnection through school, church and extended family relationships. Most families with one or more ill children had not sought medical care and declined medical assessment and laboratory testing.

\section{Case finding and data collection activities}

Confirmed, probable and suspect measles cases are reportable under the Communicable Disease Regulations under the Public Health Act in British Columbia (9). The provincial case definition for measles was used for classification of cases, but modified to include 'epidemiologically-linked confirmed' (epi-linked) cases, i.e., students and staff of the affected school that had measles-compatible clinical illness (10). This was based on the assumption that school attendance resulted in potential for measles exposure on par with exposure to a laboratory-confirmed case.

A modified abbreviated case report form based on the provincial form for measles reporting was used during the outbreak and submitted for data entry to the BC Centre for Disease Control. The provincial case report form was submitted on each case at the end of the outbreak (11). Variables included demographic data, signs and symptoms, immunization history, complications and outcome, laboratory samples collected, travel and exposure history, healthcare worker occupation, student status, residence in a communal setting and aggregate information about contacts.

\section{Laboratory methods}

The British Columbia Public Health Microbiology and Reference Laboratory performed molecular testing for detection of viral RNA on nasopharyngeal swabs and urine by reverse transcription real-time polymerase chain reaction (RT-PCR). Serologic testing was conducted using the Siemens Enzygnost $\circledast$ Anti-Measles-Virus/lgG and Anti-Measles-Virus/lgM immunoassays. The National Microbiology Laboratory (NML) in Winnipeg performed confirmatory RT-PCR testing and conducted virus genotyping for all RT-PCR-confirmed specimens.

\section{Public health measures}

Recognizing the high probability of spread of measles from the Netherlands to the associated BC population, local Fraser Health Authority health units had made concerted efforts prior to this outbreak in the summer of 2013 to strengthen relationships with the Dutch Reformed communities, particularly with the schools operated in association with churches. These relationships were facilitated by a community resource nurse employed by Fraser Health Authority who was a member of the Dutch Reformed community. Advice was also sought from public health professionals in the South Zone of Alberta where similar communities reside. Recognizing that most community members would not accept measles vaccine even in the context of the outbreak, discussion between public health authorities and the community focused on common values and goals. Values included shared responsibility for community well-being, the need to protect vulnerable members of society and the desire not to inflict harm. Goals included timely reporting of cases, minimizing transmission outside of the community and optimizing infection control measures.

Case and contact management was conducted according to BC measles control guidelines (12). Post-exposure prophylaxis with measles, mumps and rubella (MMR) vaccine as well as immune globulin (IG) were offered. Almost all contacts within the religious community declined vaccine but IG receipt was deemed in keeping with 
religious doctrine because it was seen by the community as 'treatment'. Community members willing to be vaccinated were provided with private venues to obtain this service to avoid being ostracized by their faith community. Cases were advised to self-isolate following prodrome onset and for four days following rash onset and exposed individuals to self-quarantine for a period of 21 days. Arrangements were made with hospital laboratories for diagnostic services through an alternate payment mechanism for community members without Medical Service Plan numbers. Laboratory testing was not encouraged by the public health nurses once the outbreak was confirmed to avoid exposing the general public in settings such as waiting rooms following some potential exposures in local health care settings.

Fraser Health Authority rapidly instituted control measures in the Fraser Valley area and worked alongside many groups within the affected community including school and religious leaders. Since the outbreak started the week before spring break, families of cases and contacts were asked not to travel. These travel restrictions were agreed upon with the school board and were supported by community leaders. The principal closed the school on March 7 , two days prior to spring break and under order of the medical health officer, the school remained closed for an additional week beyond the break, reopening on April 1.

Fraser Health Authority also advised measles vaccination for unvaccinated and under-vaccinated residents of the area through a variety of communications and immunization services that were offered by the health authority as well as through local pharmacies and physician's offices. For the surrounding population that accepted vaccine, MMR vaccine was offered as a second dose to toddlers as early as one month after the first dose (otherwise, the routine schedule in BC provides a second dose at four to six years). All Fraser Health Authority staff were required to have proof of measles immunity in order to work in a patient care setting. The outbreak was declared over on April 29.

\section{Statistical analysis}

Descriptive statistics were calculated using Stata 13 (StataCorp. (2013). Stata Statistical Software: Release 13. College Station, TX: StataCorp LP).

\section{Results}

A total of 433 cases (325 confirmed and 108 probable) were identified among BC residents during the outbreak. The index case had rash onset on February 22, 2014 (epi-week 8). Identified congregate settings where transmission from this case occurred were at church on the second day of the rash and school on the third day. Most cases (425, 98\%) had rash onset in March and April (epi-weeks 10 to 16) and the last case had rash onset on June 9, 2014 (epi-week 24) (Figure 1).

Figure 1: Measles outbreak epidemic curve by case status and epidemiologic week of rash onset, British Columbia, 2014

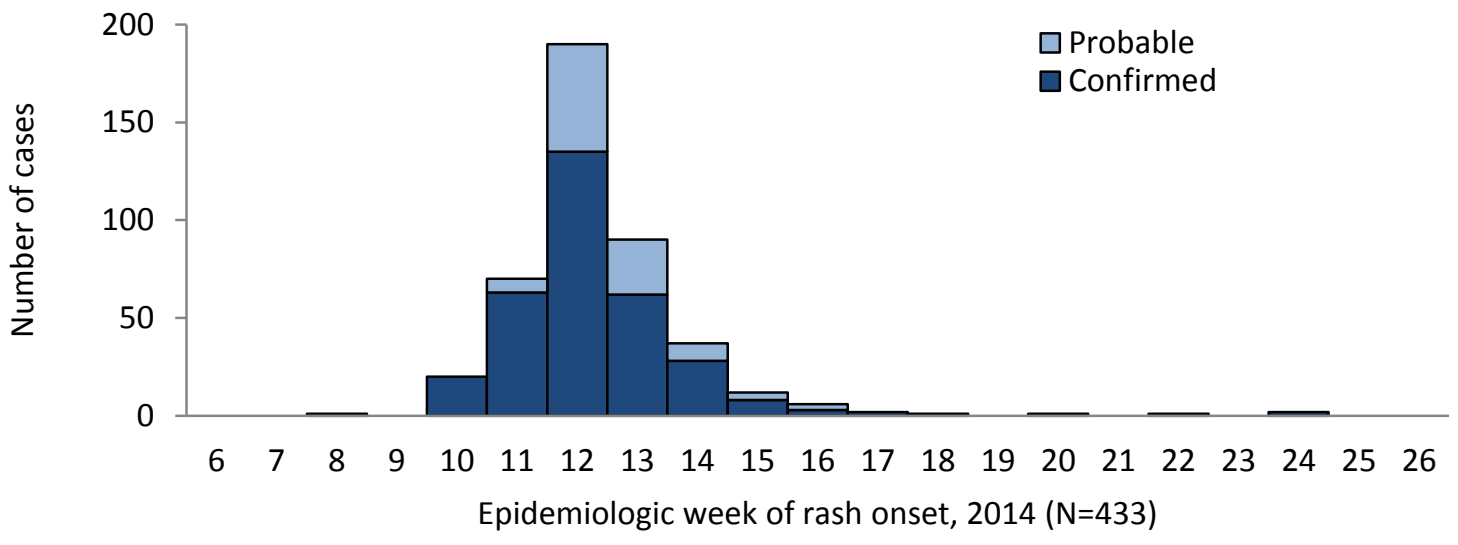


The outbreak was focused in one school in the region, which had approximately 360 students from kindergarten to grade 12. Over half of all cases were students or staff of this school (248 cases, $57 \%$; 13 laboratory-confirmed and 235 epi-linked).

There were 33 (8\%) laboratory-confirmed cases (29 by PCR and four by lgM serology), 108 (25\%) probable cases and $292(67 \%)$ epi-linked cases (Table 1). The age distribution of cases is shown in Table 1. The median age was 11 years. Among all 433 cases, only nine (two percent) were under one year of age, $70(16 \%)$ were one to four years, $295(68 \%)$ were among school-age children five to 19 years and 59 cases (14\%) were 20 to 44 years. Confirmed cases were less likely to be under five years of age and more likely to be five to 19 years (Figure 2), likely an artifact of the school attendance component of the epi-linked case definition. Fifty-one percent of cases were male.

Table 1: Characteristics of outbreak cases by case status, British Columbia, ${ }^{*} 2014$

\begin{tabular}{|c|c|c|c|c|c|c|}
\hline \multirow[t]{2}{*}{ Characteristic } & \multicolumn{2}{|c|}{$\begin{array}{c}\text { Confirmed cases } \\
\mathrm{N}=325\end{array}$} & \multicolumn{2}{|c|}{$\begin{array}{c}\text { Probable cases } \\
\qquad N=108\end{array}$} & \multicolumn{2}{|c|}{$\begin{array}{c}\text { All cases } \\
\mathrm{N}=433\end{array}$} \\
\hline & $\mathbf{n}$ & $\%$ & $\mathbf{n}$ & $\%$ & $\mathbf{n}$ & $\%$ \\
\hline \multicolumn{7}{|l|}{ Case classification } \\
\hline PCR confirmed & 29 & - & - & - & 29 & 7 \\
\hline IgM confirmed & 4 & - & - & - & 4 & 1 \\
\hline Epi-linked & 292 & - & - & - & 292 & 67 \\
\hline Probable & - & - & 108 & - & 108 & 25 \\
\hline \multicolumn{7}{|l|}{ Age group (years) } \\
\hline$<1$ & 2 & 1 & 7 & 6 & 9 & 2 \\
\hline 1 to 4 & 16 & 5 & 54 & 50 & 70 & 16 \\
\hline 5 to 9 & 115 & 35 & 4 & 4 & 119 & 27 \\
\hline 10 to 19 & 161 & 50 & 15 & 14 & 176 & 41 \\
\hline 20 to 44 & 31 & 10 & 28 & 26 & 59 & 14 \\
\hline \multicolumn{7}{|l|}{ Sex } \\
\hline Male & 166 & 51 & 56 & 52 & 222 & 51 \\
\hline Female & 159 & 49 & 52 & 48 & 211 & 49 \\
\hline \multicolumn{7}{|l|}{ Objects to vaccination } \\
\hline No & 16 & 5 & 3 & 3 & 19 & 4 \\
\hline Yes & 266 & 82 & 90 & 83 & 356 & 82 \\
\hline Unknown & 43 & 13 & 15 & 14 & 58 & 13 \\
\hline \multicolumn{7}{|l|}{ Immunization history } \\
\hline 0 doses & 281 & 86 & 93 & 86 & 374 & 86 \\
\hline 1 dose documented & 1 & 0 & 2 & 2 & 3 & 1 \\
\hline 2 doses documented & 1 & 0 & 1 & 1 & 2 & 0 \\
\hline Unknown & 42 & 13 & 12 & 11 & 54 & 12 \\
\hline
\end{tabular}

One resident of Washington State developed measles following exposure in Fraser East and was the source of infection for five additional cases reported in Washington State. These six cases are not included among the 433 described here.

Figure 2: Number of cases by age group and case status

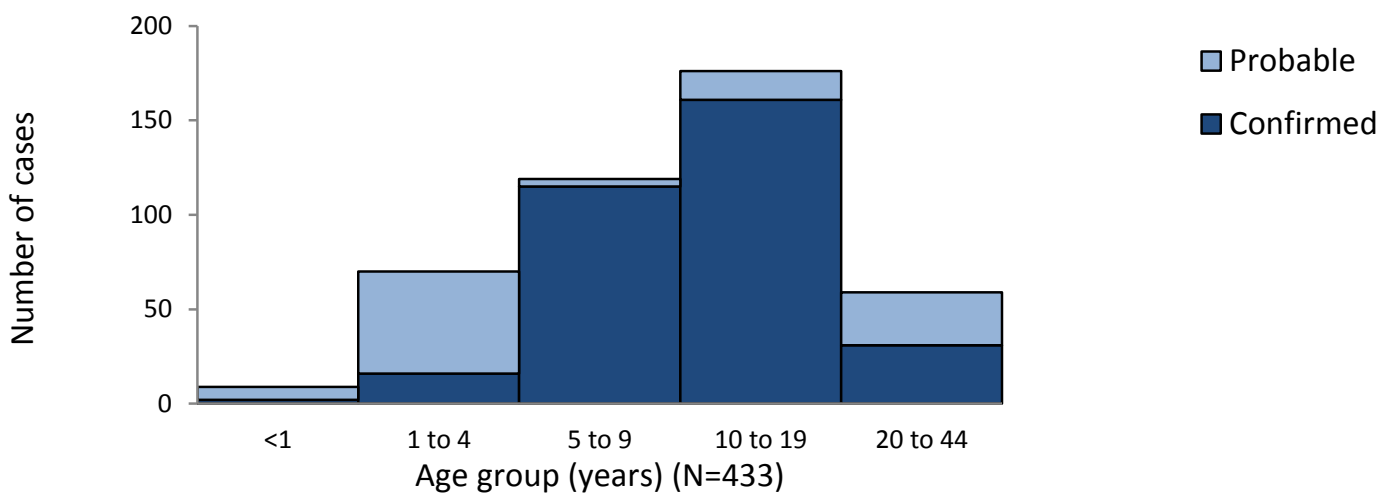


Most cases (356 cases, $82 \%$ ) reported objection to vaccination and only 19 cases (4\%) reported non-objection. This status was not reported for 58 cases $(13 \%)$. Only five cases (one percent) reported prior receipt of at least one dose of MCV. The sex distribution and vaccination status were similar for confirmed and probable cases. None of the outbreak cases reported travel during their exposure period. Three cases had pneumonia, one case had a febrile seizure and one case had encephalitis and recovered. There were five hospitalizations and no fatal outcomes. Only five cases were identified in individuals who were not members of the religious community, including three cases from one family cluster with two unvaccinated children and two cases who reported receipt of two doses of MMR vaccine. Spread outside of the religious community was also contained by relatively high rates of measles vaccine coverage. In the region overall, $90 \%$ of 7 -year olds were complete for two doses of MCV in 2014.

The measles virus genotype was D8 for 28 PCR confirmed cases. Of these, 27 were identical to the MVs/Taunton.GBR/27.12 sequence variant (the same as the strain associated with the Netherlands outbreak) and one was $99.8 \%$ identical.

\section{Discussion}

This large 2014 BC measles outbreak in a faith-based community known for low-vaccination rates largely affected the pediatric-age population which is compatible with acquisition of measles immunity by adult members due to prior wild-type measles infection. The epicenter was a school which facilitated rapid and intense transmission. Although vaccine hesitancy persisted in this population, containment of the outbreak was facilitated by a high degree of community cooperation with infection control measures and restriction of movement.

While 433 cases were reported, the true number of cases is likely to have been higher as this community is known to not seek medical diagnosis and treatment. Many members of this community do not subscribe to the provincial health care plan and cannot be tracked in administrative data bases. The outbreak was contained to the affected community with only five cases reported among non-community members despite recognized potential transmission events including on public transit, in health care facilities and in post-secondary educational institutions. This suggests adequate population-level immunity in the surrounding community despite suboptimal coverage rates as assessed at specified milestones.

One of the strengths of the outbreak response was the prior formation of a productive working relationship between local public health and the leadership in the Dutch Reformed communities. The relationship that was built with the community prior to this outbreak proved invaluable as a level of trust had already been established. The use of a nurse with direct ties to the community further enhanced communication and comfort level between the community and the health authority. This relationship allowed the community to play an active role in controlling the spread of the outbreak while maintaining their own faith-based practices. Timely reporting and community compliance and enforcement of public health measures, particularly travel restrictions during the critical spring break period, prevented measles cases from reaching denser population areas where further transmission could have occurred.

Faith-based unvaccinated communities remain vulnerable to vaccine preventable diseases. Such communities have experienced episodic outbreaks of polio, measles, rubella and mumps with transmission across international borders due to frequent travel to visit family and friends in related communities (13-17). Local public health units serving such communities are increasing their capacity and shared learning from each other's experiences to tailor their response to optimize outbreak control for these populations.

\section{Acknowledgements}

Many staff of Fraser Health Authority were involved in data collection during the outbreak. The BC Public Health Microbiology and Reference Laboratory conducted all diagnostic testing for measles and the National Microbiology Laboratory, Public Health Agency of Canada, conducted confirmatory testing and genotyping. 


\section{Conflict of interest}

None

\section{References}

(1) King A, Varughese P, De Serres G, Tipples GA, Waters J. Working Group on Measles Elimination. Measles elimination in Canada. J Infect Dis. 2004 May 1;189 Suppl 1:S236-42.

(2) BC Centre for Disease Control. Communicable disease control manual, Chapter 2: Immunization, Section IA, Introduction. 11.0 History of immunization in BC. Page 31. Vancouver BC: BCCDC; May 2009.

http://www.bccdc.ca/NR/rdonlyres/EB07BC36-BF2D-47A6-BF44-

DC286F762E9F/0/SectionIA_IntroductionJune2014.pdf.

(3) Public Health Agency of Canada. Elimination of measles, rubella and congenital rubella syndrome in Canada:

Documentation and verification report. Submitted to the Pan American Health Organization/ World Health

Organization. Ottawa ON: PHAC; December 2011. Executive summary available at: http://www.phac-

aspc.gc.ca/im/vpd-mev/measles-rougeole-mrer-eng.php.

(4) BC Centre for Disease Control. British Columbia annual summary of reportable diseases 2010. Measles. Page 20.

Vancouver BC : BCCDC; 2012. http://www.bccdc.ca/NR/rdonlyres/6F0D23A6-18E8-4983-AE53-

A7F0C7F0D91B/0/2010CDAnnualReportFinal.pdf.

(5) Gardy JL, Naus M, Amlani A, Chung W, Kim H, Tan M, Severini A, Krajden M, Puddicombe D, Sahni V, Hayden AS, Gustafson R, Henry B, Tang P. Whole-genome sequencing of H1 and D8 genotype measles outbreaks following the Olympic Winter Games reveals viral transmission routes. 2015. J. Infect. Dis. In press.

(6) Knol M, Urbanus A, Swart E, Mollema L, Ruijs W, van Binnendijk R, Te Wierik M, de Melker H, Timen A, Hahné S. Large ongoing measles outbreak in a religious community in the Netherlands since May 2013. Euro Surveill. 2013 Sep 5;18(36):pii=20580. http://eurosurveillance.org/ViewArticle.aspx?Articleld=20580.

(7) Netherlands National Institute for Public Health and the Environment. Ministry of Health, Welfare and Sport [Internet]. Measles. Bilthoven NL: RIVM; 2015. http://www.rivm.nl/en/Topics/M/Measles.

(8) Vivian Suttorp. Presentation at the Western Canada Immunization Forum, March 2014. Thursday March 6th, Day 2, Morning Plenary. http://www.health.alberta.ca/professionals/Western-Canada-Immunization-Forum.html.

(9) Public Health Act. Health Act Communicable Disease Regulation. B.C. Reg. 4/84 O.C. 6/83 http://www.bclaws.ca/.

(10) British Columbia Centre for Disease Control. Measles case definition. Vancouver BC: BCCDC; 2014. http://www.bccdc.ca/dis-cond/a-z/ m/Measles/Measlecase.htm.

(11) BC Centre for Disease Control. Measles Case Report Form. Vancouver BC: BCCDC; 2014. http://www.bccdc.ca/NR/rdonlyres/2AD4360A-9AB4-440B-B522-

5A96046D6250/0/Measles_ProvSurveillanceForm_20140918.pdf.

(12) BC Centre for Disease Control. Communicable disease control. Chapter I: Management of specific diseases. Measles. Vancouver BC: BCCDC; 2015. http://www.bccdc.ca/dis-cond/comm-manual/CDManualChap1.htm.

(13) Ofner M, Naus M, Martin E, Stolk B. Community surveillance for wild poliovirus in Ontario, 1993. CCDR. 1994;20:214216. Reprinted in CMAJ. 1995;152(12):1997-1998.

(14) van Steenbergen JE, van den Hof S, Langendam MW, van de Kerkhof JHTC, Ruijs WLM. Measles outbreak Netherlands, April 1999 - January 2000. MMWR. 2000;49(14):299-303. http://www.cdc.gov/mmwr/preview/mmwrhtml/mm4914a2.htm.

(15) Jansen VA, Stollenwerk N, Jensen HJ, Ramsay ME, Edmunds WJ, Rhodes CJ. Measles outbreaks in a population with declining vaccine uptake. Science. 2003;301:804; PMID:12907792. http://dx.doi.org/10.1126/science.1086726.

(16) Hahné S, Macey J, van Binnendijk R, Kohl R, Dolman S, van der Veen Y, et al. Rubella outbreak in the Netherlands, 2004-2005: High burden of congenital infection and spread to Canada. Pediatr Infect Dis J. 2009;28:795-800; PMID:19710586. http://dx.doi.org/10.1097/INF.0b013e3181a3e2d5.

(17) Wielders CC, van Binnendijk RS, Snijders BE, Tipples GA, Cremer J, Fanoy E, Dolman S, Ruijs WI, Boot HJ, de Melker HE, Hahné SJ. Mumps epidemic in orthodox religious low-vaccination communities in the Netherlands and Canada, 2007 to 2009. Euro Surveill. 2011 Oct 13;16(41). pii: 19989. 